\title{
Conditional survival analysis for concrete bridge decks
}

\author{
Azam Nabizadeh $^{1} \cdot$ Habib Tabatabai $^{1}\left[\right.$ Mohammad A. Tabatabai ${ }^{2}$
}

Received: 10 July 2019 / Accepted: 9 November 2019 / Published online: 21 November 2019

(c) The Author(s) 2019

\begin{abstract}
Bridge decks are a significant factor in the deterioration of bridges, and substantially affect long-term bridge maintenance decisions. In this study, conditional survival (reliability) analysis techniques are applied to bridge decks to evaluate the age at the end of service life using the National Bridge Inventory records. As bridge decks age, the probability of survival and the expected service life would change. The additional knowledge gained from the fact that a bridge deck has already survived a specific number of years alters (increases) the original probability of survival at subsequent years based on the conditional probability theory. The conditional expected service life of a bridge deck can be estimated using the original and conditional survival functions. The effects of average daily traffic and deck surface area are considered in the survival calculations. Using Wisconsin data, relationships are provided to calculate the probability of survival of bridge decks as well as expected service life at various ages. The concept of survival dividend is presented and the age when rapid deterioration begins is defined.
\end{abstract}

Keywords Survival analysis · Conditional survival · Bridge decks · Hypertabastic distribution · Expected life · Reliability Service life $\cdot$ Remaining service life

\section{Introduction}

As the average age of bridges in the U.S. continues to increase (ASCE 2018), there is a growing need to develop field performance-based probabilistic tools that could help guide bridge maintenance decisions. Large-scale data obtained from biannual bridge inspections can be particularly informative and beneficial by providing the necessary input for the development of observation-based probabilistic models for bridge deterioration with time.

Bridge decks are a significant factor influencing the deterioration of bridges, and substantially affect long-term bridge maintenance decisions (Tabatabai et al. 2015, 2016 and Brown et al. 2014). Strength-based reliability of bridge

Habib Tabatabai

ht@uwm.edu

Azam Nabizadeh

azam@uwm.edu

Mohammad A. Tabatabai

mtabatabai@mmc.edu

1 Department of Civil and Environmental Engineering, University of Wisconsin, Milwaukee, WI 53211, USA

2 School of Graduate Studies and Research, Meharry Medical College, Nashville, TN 37208, USA decks has been studied for many years providing important measures of structural safety. However, the end of service life is typically a result of serviceability issues and not due to local or global structural failure. Survival analysis is a set of observation-based and data-driven reliability techniques that has been commonly used in biomedical and cancer research (Tabatabai et al. 2007; Bursac et al. 2008). More recently, survival analysis techniques have been employed in reliability and remaining service life assessments of bridges (Tabatabai et al. 2011, 2015, 2016, 2018).

Parametric survival analysis of bridge decks based on the National Bridge Inventory (NBI) records for the State of Wisconsin was introduced by Tabatabai et al. (2011). Using the $2005 \mathrm{NBI}$ data, the authors investigated the best fit survival model among Weibull, log-logistic, lognormal, and hypertabastic survival functions. Based on the Akaike Information Criteria (AIC), the authors concluded that the hypertabastic accelerated failure time model would best fit the data. Later, the same researchers extended the survival analysis of bridge decks to six states in northern United States (Tabatabai et al. 2016) and subsequently to all fifty states and Puerto-Rico (Tabatabai et al. 2015). In these studies, the covariates considered (obtained from NBI records) were the age of bridge, deck surface area (DA), average daily traffic (ADT), and type of superstructure 
(steel or concrete). It is important to note that, as actual field observation data, the NBI information analyzed necessarily includes the combined effects of all factors influencing the outcome (service life of decks) in these field bridges. The covariates selected can be used to explicitly isolate and quantify (probabilistically) the influence of those selected covariates on the outcome. The effects of all other influencing factors are still embedded in the results, even though they are not explicitly quantified through inclusion as covariates.

Nabizadeh (2015) and Nabizadeh et al. (2018) conducted parametric survival analyses of bridge superstructures in the state of Wisconsin. In these studies, the covariates used were the age of bridge, maximum span length (MSL), ADT, and the type of superstructure (steel or concrete). Other studies on survival analysis of bridges include Beng and Matsumoto (2012), Yang et al. (2013), and Mauch and Madanat (2001).

The results of parametric survival analyses can provide estimates of survival as a function of time under the influence of various covariates. Survival is synonymous with reliability, i.e., probability of not failing at a given time. In this paper, "failure" is defined as the end of service life (and not structural failure). Figure 1 shows a typical survival curve for bridge decks. This type of survival curve is a representation of variation of reliability with time and is widely used in this form in various scientific fields.

The reliability/survival curve is a function of covariates used in the model. The survival curve in Fig. 1 was derived assuming that the covariates ADT and DA were equal to the mean values for the state of Wisconsin $(\mathrm{ADT}=4944$ and DA $=404 \mathrm{~m}^{2}$ ). Higher ADT and DA values would shift the curve to the left (lower reliability at a given age), while lower values of those covariates would shift the curve to the right. The survival function, $S(t)$, is defined as

$S(t)=p(T>t)=1-F(t)$,

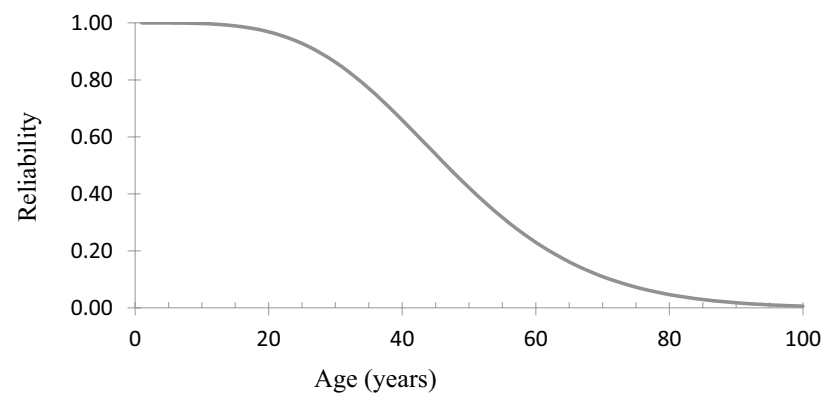

Fig. 1 Reliability of bridge decks in the state of Wisconsin (Tabatabai et al. 2011) where $t$ is the age of bridge deck (in years), $T$ is the age at the end of service life, and $F(t)$ is the cumulative distribution function. The probability density function, $f(t)$, and the hazard rate function, $h(t)$, are defined below:

$f(t)=\lim _{\Delta t \rightarrow 0} p(t<T<t+\Delta t) / \Delta t$

$h(t)=\lim _{\Delta t \rightarrow 0} p(t<T<t+\Delta t \mid T>t) / \Delta t$.

These functions are determined during survival analysis of observation-based data on bridge decks that are obtained from the NBI records. The area under the entire survival curve (integral of survival function with respect to time) is the expected life $\left(\mathrm{EL}_{0}\right)$, or average life expectancy, for a bridge that is in a brand-new condition $(t=0)$ :

$\mathrm{EL}_{0}=\int_{0}^{\infty} S(t) \mathrm{d} t$.

Based on the results of a study by Tabatabai et al. (2011) and using Eq. 4, the expected life of Wisconsin bridge decks is approximately 45 years, when ADT and deck areas are held at mean values for the state. It is important to note, however, that the expected life would change at different ages (i.e., different from $\mathrm{EL}_{0}$ ). Furthermore, estimates of life expectancy at a given age would vary depending on whether that age has been successfully achieved (i.e., without failure) or when the estimate for life expectancy at that age is made at $t=0$.

In the medical field, prognosis of a disease is generally predicted based on the information at the time of diagnosis. However, it has been shown that disease prognosis improves with every additional year that the patient survives (Baade et al. 2011; Zabor et al. 2013). Therefore, life expectancy based on the information at the time of diagnosis $(t=0)$ would need to be updated as time progresses. For example, if a patient were given 5 years to live at the time of diagnosis of a disease, the life expectancy at 2, 3, or 4 years past diagnosis would not remain the same. This statement stems from the conditional probability theory and would remain true even if conditions (including treatments) remained unchanged during the elapsed time. Similarly, a bridge deck that may have an initial life expectancy of 45 years would have changing expected life with age. There would be an increasing expected life trend as survival is confirmed at various ages. If a bridge deck has already reached 30 years of life without "failure" (defined as end of service life), then the expected survival age would be higher than the originally estimated 45 years. In this paper, this additional expected life is termed "survival dividend". The fact that a bridge deck has already survived $t_{\mathrm{s}}$ years adds an important piece of information that should be used to update the initial life 
expectancy based on the conditional probability theory. The objective of this paper is to introduce the concept of conditional survival for the assessment of service life in bridge decks, and to demonstrate its application to assessment of bridge deck service life in Wisconsin based on the 2016 NBI data.

\section{Bridge deck data}

The 2016 National Bridge Inventory (NBI) data were used to assess conditional survival of bridge decks in Wisconsin. First, using a procedure described in Tabatabai et al. (2011), the overall survival functions were determined. An NBI bridge deck rating of 5 (on a numerical scale of 0-9) was selected as the end of service life. The justification for this choice is provided by Nabizadeh et al. (2018) and is primarily based on the fact that a deck rating of 4 would automatically designate a bridge as "structurally deficient" (or "poor" in the new designation by the Federal Highway Administration) with important policy implications. Therefore, bridge owners take steps (rehabilitation or replacement) before reaching that rating level to avoid a "poor" designation.

The independent covariates used in the analyses were the bridge age, deck area, and average daily traffic (ADT). The average daily truck traffic (ADTT) was found to be correlated with $\mathrm{ADT}$ and, therefore, $\mathrm{ADT}$ alone was used as a covariate. Parameters such as deck rating (NBI Item 58), bridge age (NBI Items 90 and 27), deck area (NBI Items 49 and 51), and ADT (NBI Item 29) were used as covariates for parametric survival analysis. The complete data extraction and data analysis procedures are presented by Tabatabai et al. (2011).

\section{Conditional survival}

The conditional survival, which is symbolically represented by CS $\left(t, t_{\mathrm{s}}\right)$, gives the probability of surviving $t$ years (or $t^{\prime}$ additional years), given that the bridge deck has already survived $t_{\mathrm{s}}$ years where $t^{\prime}=t-t_{\mathrm{s}}$. As stated earlier, the additional "knowledge" gained because of the continuing survival alters the original survival function for the future, and thus the expected life would vary with survived age. The importance of using conditional survival to arrive at a meaningful measure of prognosis or expected remaining life has not been broadly understood (Zabor et al. 2013).

As bridges age, benchmark (initial) estimates of bridge survival (made at the time of start of service life, $t=0$ ) can provide inaccurate prediction of remaining service life. Over time, the additional information on bridge survival would alter the survival estimates relative to the initial survival estimates. A relevant question that may arise is: "If a bridge deck has already survived $t_{1}$ years, what is the probability that it would survive another $t_{2}$ years?"

Conditional survival analyses can directly address this question and provide estimates for the probability of survival (of bridge decks) that have already survived to a certain age. This would require knowledge of the basic reliability curves such as that shown in Fig. 1. Probabilistic estimates of conditional survival can provide important additional information that could be used by bridge maintenance engineers to support decision-making and budget allocations for the management of bridge networks. This would be an important tool to assess bridge condition with respect to service life in a probabilistic manner.

Conditional survival has seen increasing interest and has been extensively studied in medical research over the last 20 years (Merrill et al. 1999; Kato et al. 2001; Wang et al. 2007; Fuller et al. 2007; Chang et al. 2009; Janssen-Heijnen et al. 2010; Xing et al. 2010; Merrill and Hunter 2010; Zamboni et al. 2010; Parsons et al. 2011; Baade et al. 2011; Yu et al. 2012; Harshman et al. 2012; Zabor et al. 2013; Hieke et al. 2015). These studies address changes in the probability of survival or expected life for various diseases and conditions.

While some studies have investigated the survival of bridges around the world, the authors of this paper have not identified any work that addresses conditional survival of bridges with respect to the end of service life, which is typically reached due to serviceability conditions. There are works that address changes in the reliability index over time (Zhu et al. 2017; Sun and Hong 2001; Akgul and Frangopol 2003; Kong and Frangopol 2003; Barone and Frangopol 2014). These studies, however, are not typically related to field observation-based end of service life resulting from serviceability conditions.

The survival function, $S(t)$, described above provides estimates of reliability over time based on information available at $t=0$. This is referred to here as overall survival (OS). $O S$ does not include the influence of knowledge gained when survival is realized at $t>0$. After $t_{\mathrm{s}}$ years of survival, the survival information must be updated to reflect the new knowledge gained. This is introduced in terms of conditional survival (CS) in which prior knowledge of survival at time $t_{\mathrm{s}}$ exists. CS estimates the probability of survival at time $t$, given that the bridge deck has already survived $t_{\mathrm{s}}$ years. CS can be considered as a dynamic survival estimation and is defined as

$\operatorname{CS}\left(t, t_{\mathrm{s}}\right)=\left\{\begin{array}{l}1 \text { when } 0 \leq t \leq t_{\mathrm{s}} \\ \frac{S(t)}{S\left(t_{\mathrm{s}}\right)} \text { when } t>t_{\mathrm{s}}\end{array}\right.$.

The above equations indicate that, given the fact that survival has been achieved up to time $t_{\mathrm{s}}$, the conditional 
probability of survival would be equal to $1(100 \%)$ at or before time $t_{\mathrm{s}}$. The originally estimated survival probabilities are then adjusted using Eq. (5). The change in the probability of survival at times greater than $t_{\mathrm{s}}$ (as reflected in Eq. 5) also changes the expected life beyond time $t_{\mathrm{s}}$.

The probability of failure defined here is based on conditional survival analysis. Probability of failure indicates reaching the end of service life at a specific age of bridge (1 minus probability of survival at a specific age). CS is then calculated relative to varying survival times.

The hypertabastic accelerated failure time model, first introduced by Tabatabai et al. (2007), was used for the analyses. This model was determined to be the best fit model for bridge deck and superstructure data when compared with Weibull, log-logistic and lognormal models (Tabatabai et al. 2011; Nabizadeh et al. 2018). The hypertabastic distribution has been used in several studies including biomedical and engineering survival analyses (Tabatabai et al. 2007; Tran 2014; Nikulin and $\mathrm{Wu}$ 2016; Tahir et al. 2017).

The theoretical basis and complete equations for the hypertabastic model are given in Tabatabai et al. (2011). Therefore, in this paper, only the equations and parameters needed to calculate reliability and failure rates are provided. These are summarized below:

$S(t)=\operatorname{sech}\left\{W\left(t_{\mathrm{g}}\right)\right\}$,

$h(t)=\alpha\left[t^{2 \beta-1} \operatorname{Csch}^{2}\left(t^{\beta}\right)-t_{\mathrm{g}}^{\beta-1} \operatorname{coth}\left(t_{\mathrm{g}}^{\beta}\right)\right] \tanh \left[W\left(t_{\mathrm{g}}\right)\right] e^{[c(\mathrm{DA})+d(\mathrm{ADT})]}$,

$t_{\mathrm{g}}=(t) e^{[c(\mathrm{DA})+d(\mathrm{ADT})]}$,

$t_{\mathrm{g}}=(t) e(\mathrm{DA}) \mathrm{CADT}$,

$W\left(t_{\mathrm{g}}\right)=\alpha\left[1-t_{\mathrm{g}}^{\beta} \operatorname{coth}\left(t_{\mathrm{g}}^{\beta}\right)\right] / \beta$.

In Eq. (8), parameter $t_{\mathrm{g}}$ is defined as a mathematical function of $t$ (age of bridge in years), DA (bridge deck surface area in $\mathrm{m}^{2}$ ), and ADT. Parameters $\alpha, \beta, c$, and $\mathrm{d}$ are all determined for bridges in Wisconsin, using the procedures proposed by Tabatabai et al. (2011). Functions sech and coth are hyperbolic secant and hyperbolic cotangent, respectively.

Several different survival analyses were performed in this study using different subsets of the extracted NBI data. The full analysis $\left(D_{0}\right)$ involved all bridge data that were extracted from the NBI records. In addition, several subsets of the full data were chosen for analysis. These data subsets included all bridge records that had survival times greater than specified ages from 20 to 50 years at 5-year increments $\left(t_{\mathrm{s}}=20\right.$, $25,30,35,40,45$, and 50 years). Each dataset analyzed is designated " $D_{\mathrm{t}}$ " with " $t_{\mathrm{s}}$ " indicating the length of time (years) that bridge deck has already survived. Thus, the full data set $\left(D_{0}\right)$ as well all other subsets $\left(D_{20}, D_{25}, D_{30}, D_{35}\right.$, $D_{40}, D_{45}$, and $D_{50}$ ) were analyzed separately to determine the survival functions associated with them. This was done to assess the accuracy of the proposed CS models with available data as the survival age increases. The conditional survival function for bridge decks can be calculated by solving Eq. (5) using survival function of Eq. (6).

\section{Analysis of NBI data}

Descriptive statistics of NBI data for all bridges used in this study is shown in Table 1. As discussed earlier, survival analyses were performed on multiple subsets of the full dataset. First, analyses were performed to determine the survival functions for all bridges in the dataset $\left(D_{0}\right.$ dataset). This would provide the overall (unconditional) survival function (Eq. 6). Using this survival function and Eq. 5, the conditional survival functions assuming survival up to various ages $\left(t_{\mathrm{s}}=20,25,30, \ldots\right.$, or 50 years) could be theoretically calculated. To check the validity of these theoretical calculations, subsets of data corresponding to various survival ages were extracted and analyzed separately. For example, to generate the $D_{35}$ dataset, all records with a bridge age of less than 35 years were excluded and the remaining data were analyzed.

Using the various datasets, the non-parametric Kaplan-Meier estimation of the survival, $S_{\mathrm{K}-\mathrm{M}}(t)$, can be calculated using the following relationship:

$S_{\mathrm{K}-\mathrm{M}}(t)=\frac{\text { No.of bridges surviving beyond tyears }}{\text { Total number of bridges }}$.

The Kaplan-Meier estimates of survival were calculated for the entire dataset as well as all data subsets. For the data sets that are subsets of the entire data, the Kaplan-Meier estimate is, in fact, equal to the conditional Kaplan-Meier survival estimates.

$\mathrm{CS}_{\mathrm{K}-\mathrm{M}}\left(t, t_{\mathrm{S}}\right)=S_{\mathrm{K}-\mathrm{M}}(t)$ for the $D_{t_{\mathrm{s}}}$ dataset.

Figure 2 shows estimates of the non-parametric conditional Kaplan-Meier survival curves for bridge decks for

Table 1 Statistical information on the entire Wisconsin NBI dataset used in the analyses

\begin{tabular}{lrcc}
\hline Bridges with deck rating 5 & & \\
\hline & ADT & Area $\left(\mathrm{m}^{2}\right)$ & Age (years) \\
\hline Mean & 3843 & 458 & 53 \\
Median & 809 & 223 & 50 \\
Mode & 47 & 82 & 46 \\
Standard deviation & 7314 & 807 & 20 \\
Count & 1065 & 1065 & 1065 \\
\hline
\end{tabular}


Fig. 2 Kaplan-Meier survival curves for bridges that have already achieved $t_{\mathrm{s}}$ years of survival
Kaplan-Meier conditional survival for Wisconsin bridge decks

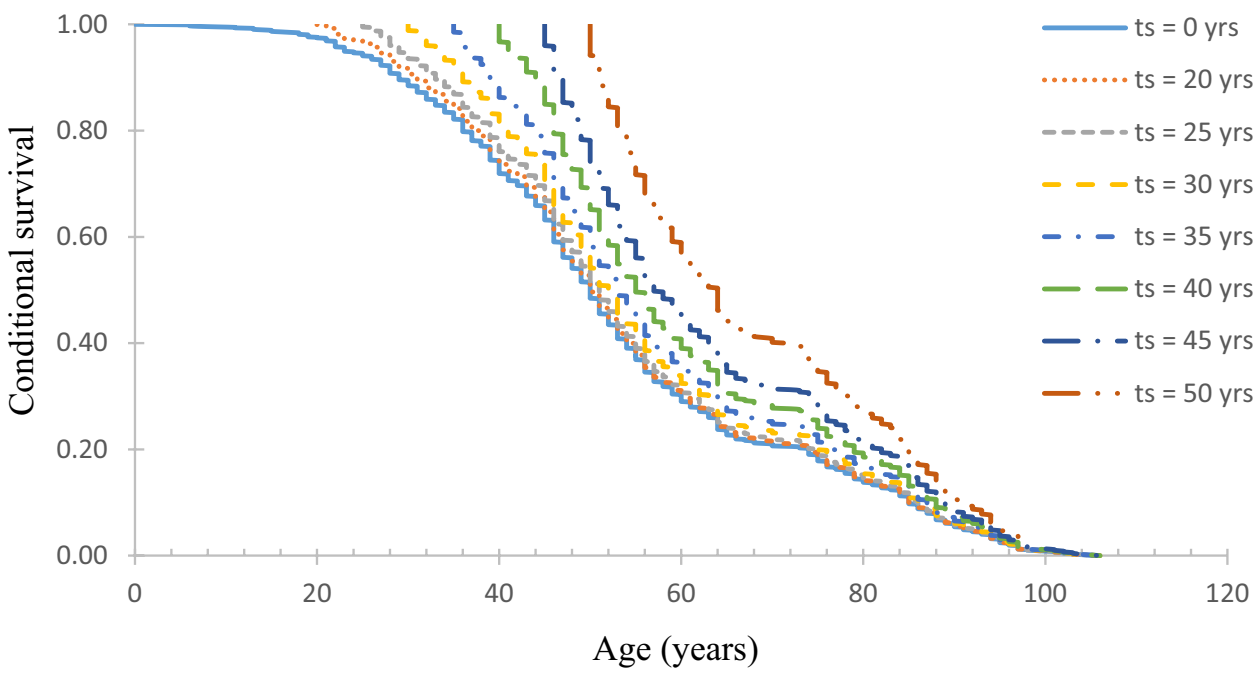

Table 2 Median and mean ages of Wisconsin bridge decks at the end of service life

\begin{tabular}{lllllc}
\hline Dataset & $\begin{array}{l}\text { Survived age }\left(t_{\mathrm{s}}\right) \\
\text { (years) }\end{array}$ & $\begin{array}{l}\text { Median age of } \\
\text { decks (years) }\end{array}$ & $\begin{array}{l}\text { Mean age of decks } \\
\text { (years) }\end{array}$ & $\begin{array}{l}\text { St. dev. of age } \\
\text { (years) }\end{array}$ & $\begin{array}{l}\text { Number } \\
\text { of bridges }\end{array}$ \\
\hline$D_{0}$ & 0 & 50.0 & 53.2 & 20.2 & 1065 \\
$D_{20}$ & 20 & 50.0 & 54.2 & 19.5 & 1040 \\
$D_{25}$ & 25 & 51.0 & 55.2 & 18.9 & 1008 \\
$D_{30}$ & 30 & 52.0 & 56.7 & 18.2 & 954 \\
$D_{35}$ & 35 & 53.0 & 58.5 & 17.5 & 889 \\
$D_{40}$ & 40 & 55.0 & 61.1 & 16.8 & 793 \\
$D_{45}$ & 45 & 57.0 & 63.6 & 16.3 & 702 \\
$D_{50}$ & 50 & 64.0 & 68.3 & 15.4 & 549 \\
\hline
\end{tabular}

Table 3 Parameter and standard error estimates of the hypertabastic AFT model

\begin{tabular}{lllcl}
\hline Parameter & Estimate & Standard error & Wald & $P$ value \\
\hline$\alpha$ & $1.29 \mathrm{E}-03$ & $2.11 \mathrm{E}-04$ & 37.42 & $9.51 \mathrm{E}-10$ \\
$\beta$ & $1.90 \mathrm{E}+00$ & $4.48 \mathrm{E}-02$ & 1796.7 & $1.34 \mathrm{E}-392$ \\
$c$ & $5.70 \mathrm{E}-05$ & $1.00 \mathrm{E}-05$ & 32.08 & $1.48 \mathrm{E}-08$ \\
$d$ & $6.93 \mathrm{E}-06$ & $1.43 \mathrm{E}-06$ & 23.39 & $1.32 \mathrm{E}-06$ \\
\hline
\end{tabular}

different $D_{\text {ts }}$ data sets. In conditional Kaplan-Meier survival, bridges that have failed prior to each considered service life $\left(t_{s}\right.$.) were removed from the analysis, as shown in Fig. 2.

The median and mean of age for bridge decks in the various datasets are shown in Table 2. These values indicate the effect on the service life of the remaining bridge decks when decks with ages less than or equal to $t_{\mathrm{s}}$ are excluded from consideration. Data show increasing mean and median ages of bridges that remain after various ages are reached.

All the datasets were then used to estimate survival parameters and equations using the procedures presented by Tabatabai et al. (2011). The method of maximum likelihood was used for parameter estimation of the hypertabastic AFT survival model. Table 3 shows the estimated values of various hypertabastic model parameters as well as related test statistics for the analysis of the main $D_{0}$ dataset.

Using the derived survival function and the resulting conditional survival functions (Eq. 5), the conditional mean (expected) life of bridge decks, $\mathrm{EL}_{c}\left(t_{\mathrm{s}}\right)$, can be calculated by integrating the survival or conditional survival functions as shown in Eq. 1:

$\mathrm{EL}_{\mathrm{c}}\left(t_{\mathrm{s}}\right)=\int_{0}^{\infty} \mathrm{CS}(t) \mathrm{d} t=t_{\mathrm{s}}+\int_{t_{\mathrm{s}}}^{\infty} \mathrm{CS}(t) \mathrm{d} t=t_{\mathrm{s}}+\int_{t_{\mathrm{s}}}^{\infty} \frac{S(t)}{S\left(t_{\mathrm{s}}\right)} \mathrm{d} t$.

The unconditional expected life, $\mathrm{EL}_{\mathrm{u}}(t)$, as a function of age can be represented as follows:

$\mathrm{EL}_{\mathrm{u}}(t)=S(t) \mathrm{EL}_{\mathrm{c}}(t)$ 


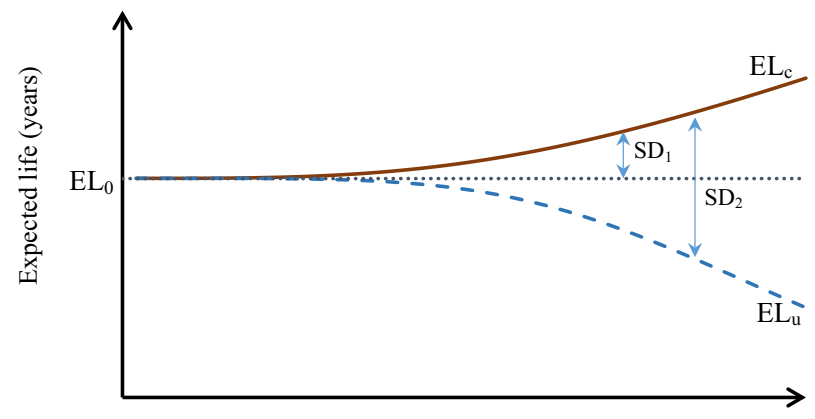

$t, t_{s}$

Fig. 3 Definition of the two types of survival dividend $\mathrm{SD}_{1}$ and $\mathrm{SD}_{2}$

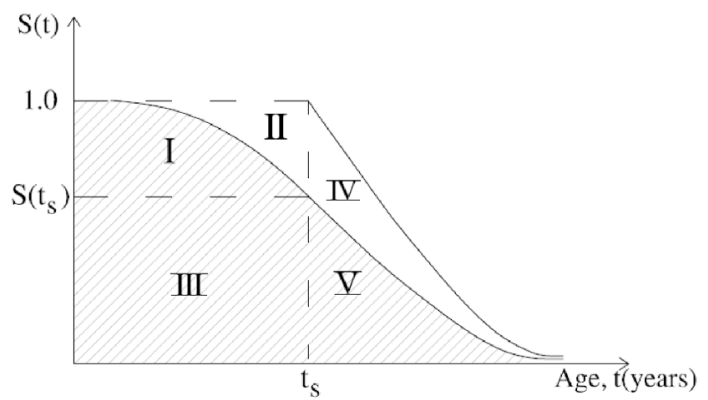

$\mathrm{EL}_{0}$

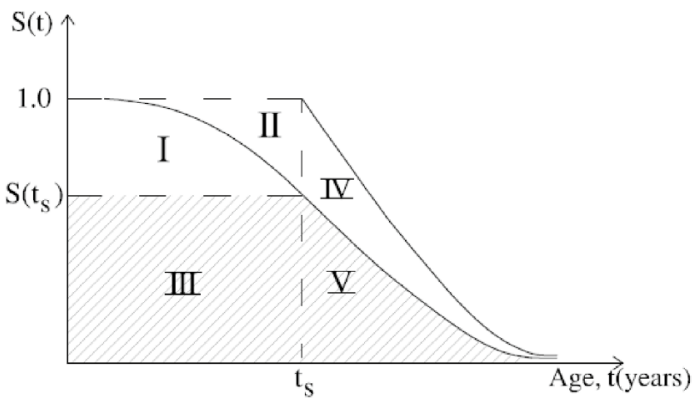

$\mathrm{EL}_{\mathrm{u}}\left(\mathrm{t}=\mathrm{t}_{\mathrm{s}}\right)$

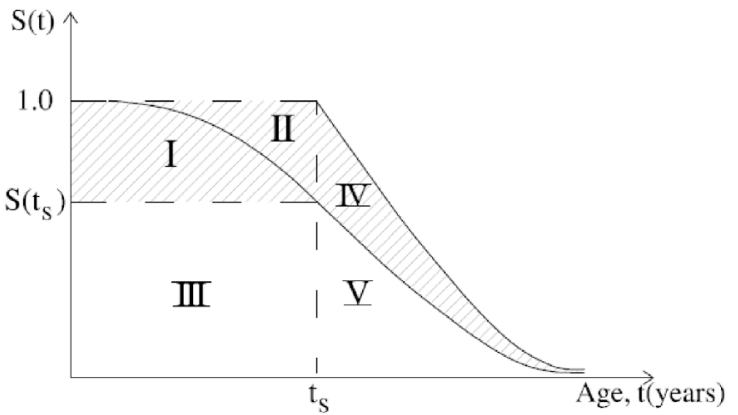

$\mathrm{SD}_{2}\left(\mathrm{t}=\mathrm{t}_{\mathrm{s}}\right)$
$\mathrm{EL}_{\mathrm{u}}(t)=S(t) t+\int_{t}^{\infty} S(t) \mathrm{d} t$

It should be noted that $\mathrm{EL}_{0}=\mathrm{EL}_{\mathrm{c}}(0)=\mathrm{EL}_{\underline{\mathrm{u}}}(0)$. Two types of survival dividend can be defined: $\operatorname{SD}_{1}\left(t_{\mathrm{s}}\right)$ relates to improvements in expected service life relative to $\mathrm{EL}_{0}$, and $S D_{2}(t)$ relates to improvements with respect to $\mathrm{EL}_{\mathrm{u}}(t)$. The two types of survival dividend are illustrated in Fig. 3.

$\mathrm{SD}_{1}\left(t_{\mathrm{s}}\right)=\mathrm{EL}_{\mathrm{c}}\left(t_{\mathrm{s}}\right)-\mathrm{EL}_{0}$,

$\mathrm{SD}_{2}\left(t=t_{\mathrm{s}}\right)=\mathrm{EL}_{\mathrm{c}}\left(t_{\mathrm{s}}\right)-\mathrm{EL}_{\mathrm{u}}\left(t=t_{\mathrm{s}}\right)$

Figure 3 shows the difference between the two survival dividend forms $\left(\mathrm{SD}_{1}\right.$ and $\left.\mathrm{SD}_{2}\right)$. Figure 4 shows a graphical

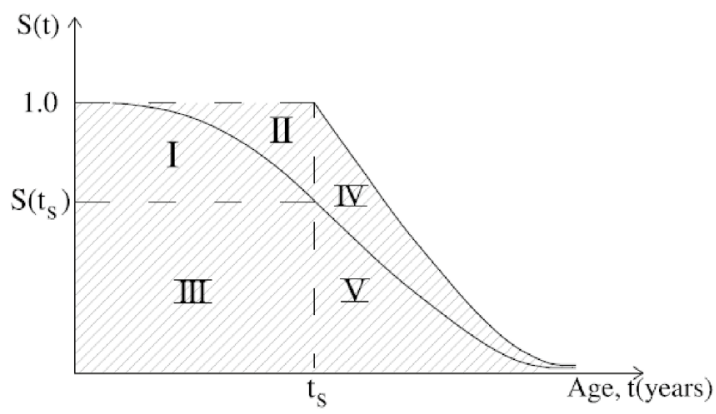

$\mathrm{EL}_{\mathrm{c}}\left(\mathrm{t}_{\mathrm{s}}\right)$

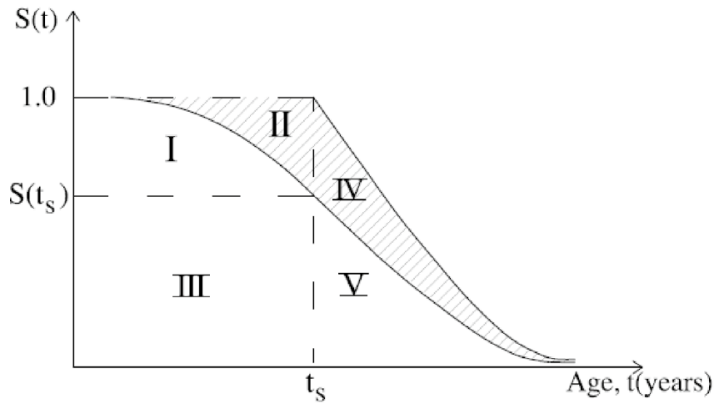

$\mathrm{SD}_{1}\left(\mathrm{t}_{\mathrm{s}}\right)$

$E L_{0}=$ Area $_{I}+$ Area $_{I I I}+$ Area $_{V}$

$E L_{c}\left(t_{s}\right)=$ Area $_{I}+$ Area $_{I I}+$ Area $_{I I I}+$ Area $_{I V}+$ Area $_{V}$

$E L_{u}\left(t_{s}\right)=$ Area $_{I I I}+$ Area $_{V}$

$S D_{l}\left(t_{s}\right)=$ Area $_{I I}+$ Area $_{I V}+$ Area $_{V}$

$S D_{1}\left(t_{s}\right)=E L_{c}\left(t_{s}\right)-E L_{0}$

$S_{2}\left(t_{s}\right)=$ Area $_{I}+$ Area $_{I I}+$ Area $_{I V}$

Fig. 4 Graphical representation and comparison between various expected life terms 
representation and comparison between various expected life terms described above $\left(\mathrm{EL}_{0}, \mathrm{EL}_{\mathrm{c}}\right.$ and $\left.\mathrm{El}_{\mathrm{u}}\right)$. The cross hatched areas (areas under the survival curve marked with Roman numerals) represent the parameters shown.

\section{Results and discussion}

Survival and hazard rate functions for bridge decks can be determined as a function of time (age) using the parameters shown in Table 3 for the hypertabastic accelerated failure time model (Eqs. 6 and 8) for all datasets. The users could use any covariate values to assess their effect on survival. However, for the following analyses, the values of the covariates DA and ADT were assumed to be equal to the mean values for the bridges in the $D_{0}$ dataset (ADT $=3843$ and $\mathrm{DA}=458 \mathrm{~m}^{2}$ ). For the $D_{0}$ (full) dataset, conditional survival estimates were made using Eq. 5 based on the $D_{0}$ dataset (Fig. 5) as well as all other $D_{t \mathrm{~s}}$ datasets (Fig. 6) for comparison purposes.

Estimated baseline survival curves (static prediction) and conditional survival curves (dynamic prediction) were determined for $t_{\mathrm{s}}$ values ranging from 20 to 50 years at 5-year increments as shown in Fig. 6. Again, it should be

Deck conditional survival based on $\mathrm{D}_{0}$ dataset (WI)

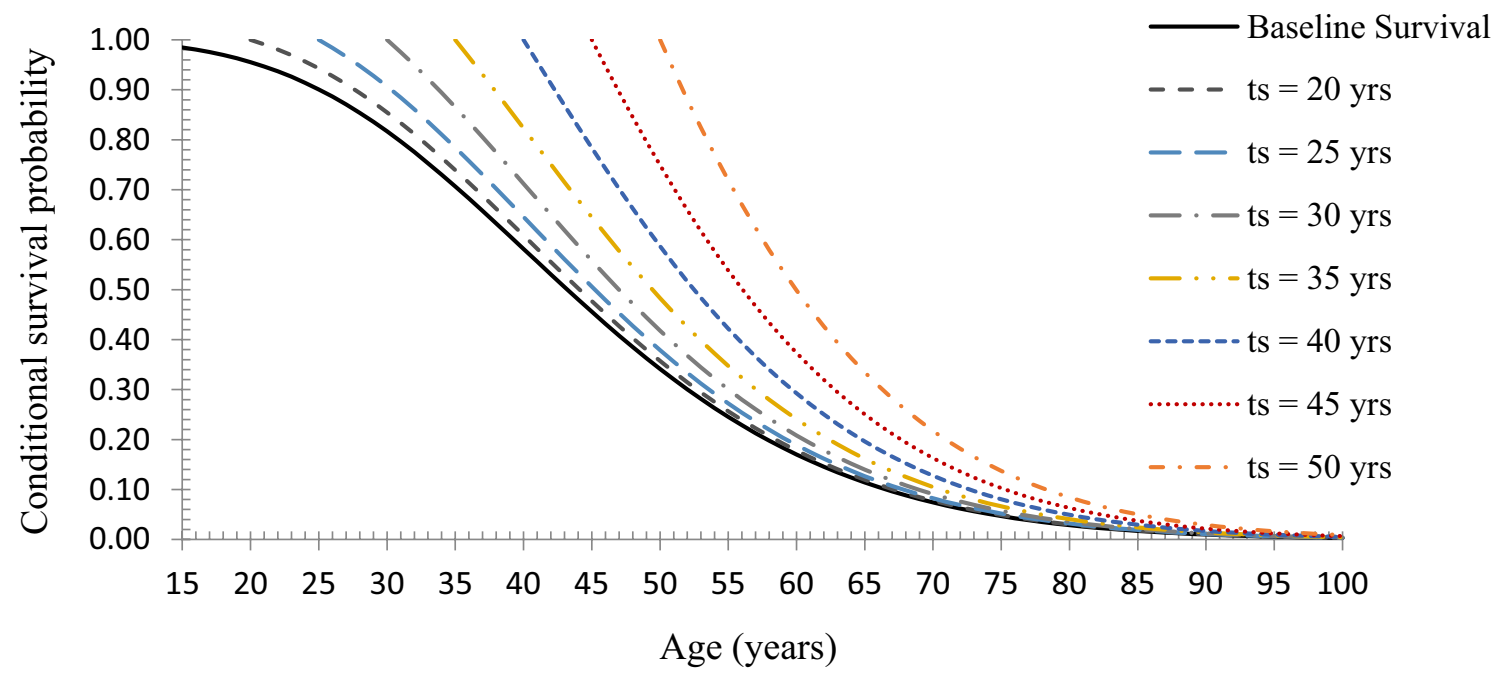

Fig. $5 C S$ of bridge decks with different $\mathrm{t}_{\mathrm{s}}$ values using $D_{0}$ dataset $(\mathrm{ADT}=3843 \mathrm{DA}=458)$

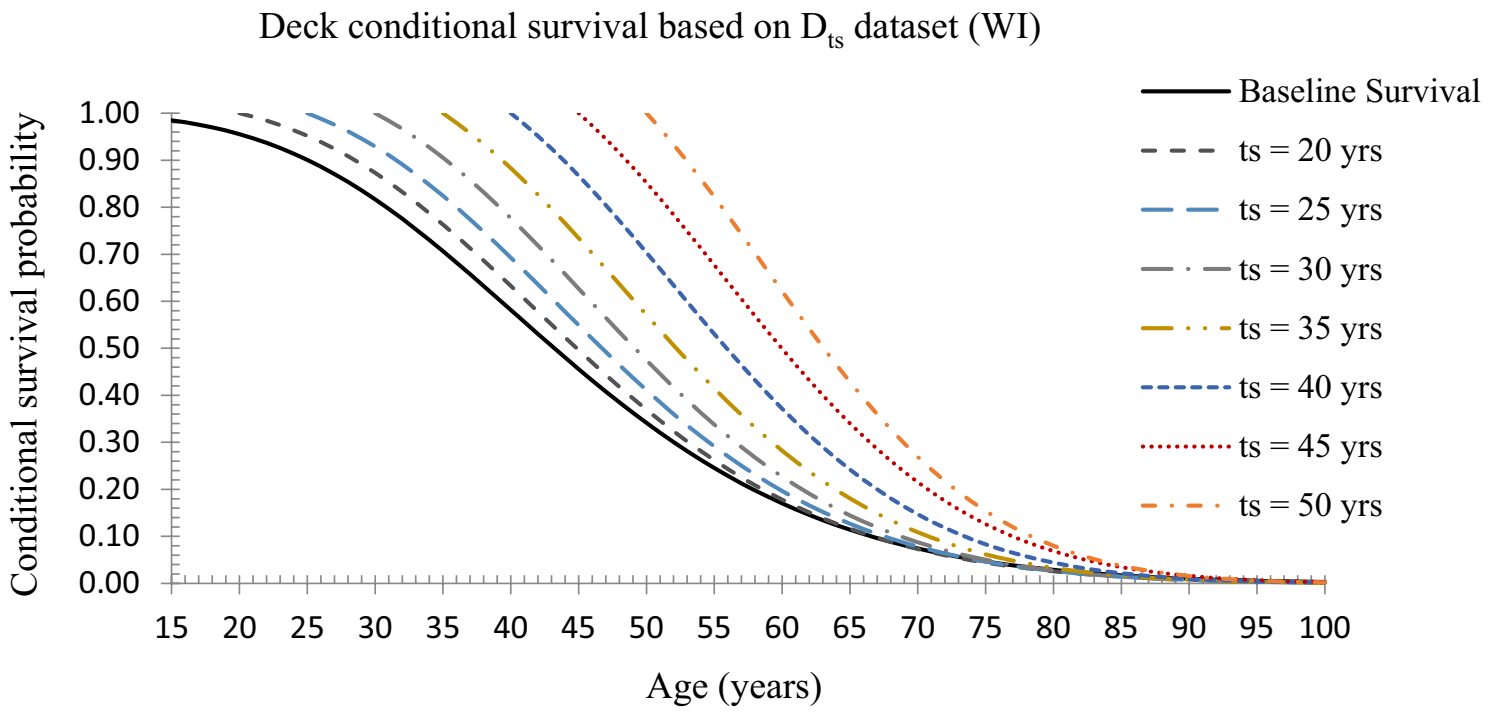

Fig. $6 \mathrm{CS}$ of bridge decks with different $\mathrm{t}_{\mathrm{s}}$ values using $D_{t \mathrm{~s}}$ datasets $(\mathrm{ADT}=3843 \mathrm{DA}=458$ ) 

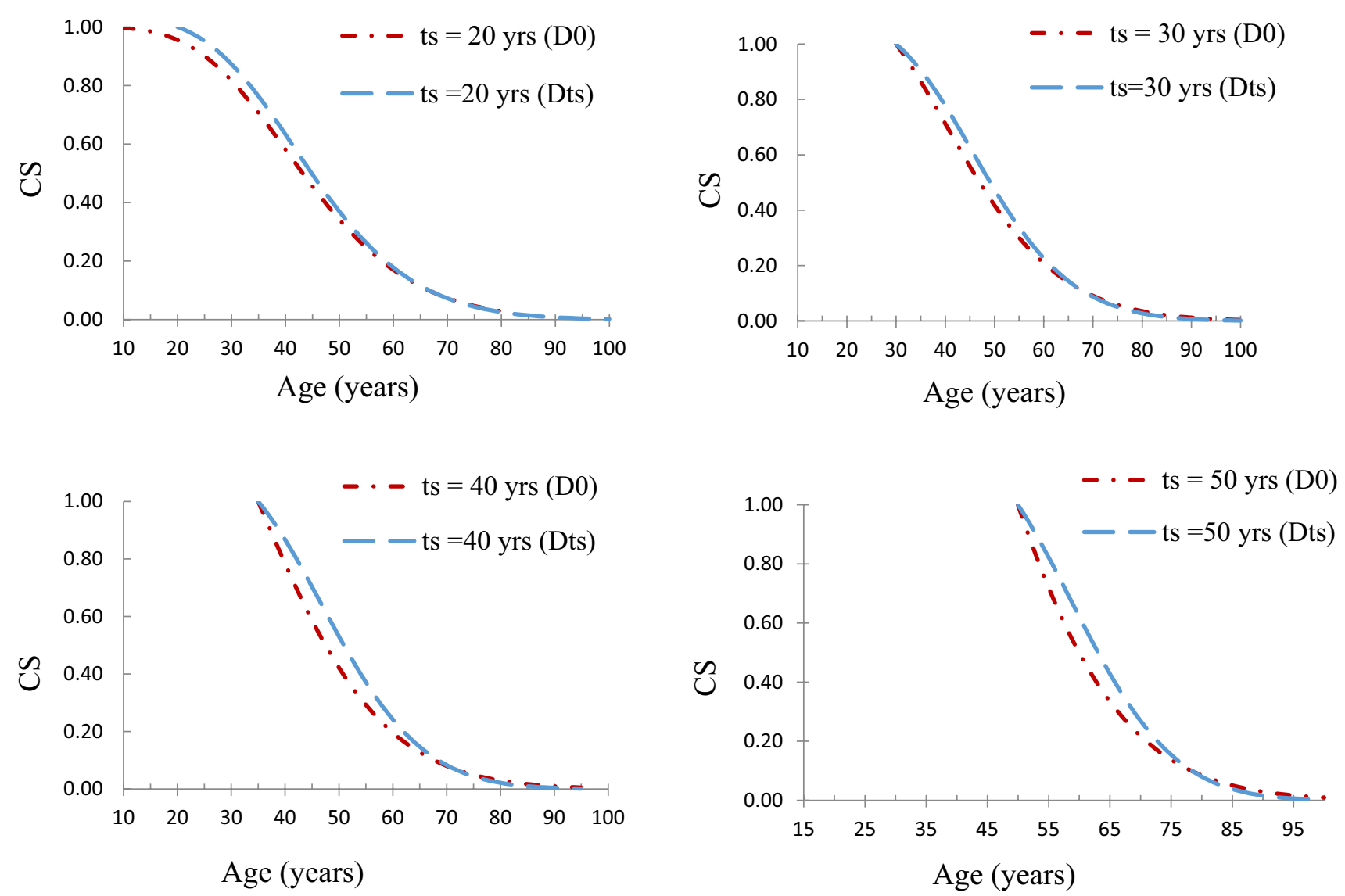

Fig. 7 Comparison of CS of bridge decks using full $\left(D_{0}\right)$ and partial $\left(D_{t s}\right)$ data sets

emphasized that the values reported are for the values of covariates assumed above. Other covariate values may be used as applicable.

Figure 7 compares the two sets of CS curves that were determined using $D_{0}$ and $D_{\text {ts }}$ datasets. These results show reasonably good agreement. Therefore, the $D_{0}$ dataset in combination with Eq. 5 can be used to accurately determine the conditional survival of bridge decks under various conditions. This would eliminate the need to sort and separate data based on the survival age.

Using the $D_{0}$ dataset, and assuming DA $=500 \mathrm{~m}^{2}$, the example values of the conditional expected life can be determined. Figure 8 shows these values as a function of $t_{\mathrm{s}}$ for various ADT levels. As $t_{\mathrm{s}}$ increases, the expected life increases as well. Figure 9 shows the conditional expected service life when ADT $=5000$ vehicles for different values of DA.

Figures 10 and 11 show variations of $\mathrm{EL}_{\mathrm{u}}$ with age when DA and ADT are fixed at $500 \mathrm{~m}^{2}$ and 5000 vehicles, respectively. A comparison of Figs. 8 and 9 with their corresponding Figs. 10 and 11 shows the full effect of achieving survival at various ages. While the unconditional expected life at various ages would continue to decrease, the conditional expected life would continuously increase as survived age increases.

Both $\mathrm{EL}_{\mathrm{c}}$ and $\mathrm{EL}_{\mathrm{u}}$ curves show approximately linear segments at the beginning and end of each curve. If straight lines are drawn at the beginning and end of each $\mathrm{EL}_{\mathrm{u}}$ curve based on linear regression analyses of data in those zones, the intersection of the two straight lines would represent an approximate transition point beyond which the rate of decline of unconditional expected life would increase significantly (Fig. 12). The intersection point is defined here as the "rapid deterioration" point with a corresponding age $t_{\mathrm{rd}}$. Values of $t_{\text {rd }}$ are calculated for various combinations of $A D T$ and $D A$ values. Tables 4 and 5 show variations of $\mathrm{EL}_{0}$ and $t_{\text {rd }}$, respectively, for different combinations of ADT and DA. The $t_{\text {rd }}$ parameter could be another factor to be considered in support of bridge deck management decisions.

From the data presented, it is evident that both ADT and DA influence the unconditional and conditional expected life as well as the probability of survival at various ages. An evaluation of the results shows that changes in ADT have larger influence on the expected life than the DA. Changing 


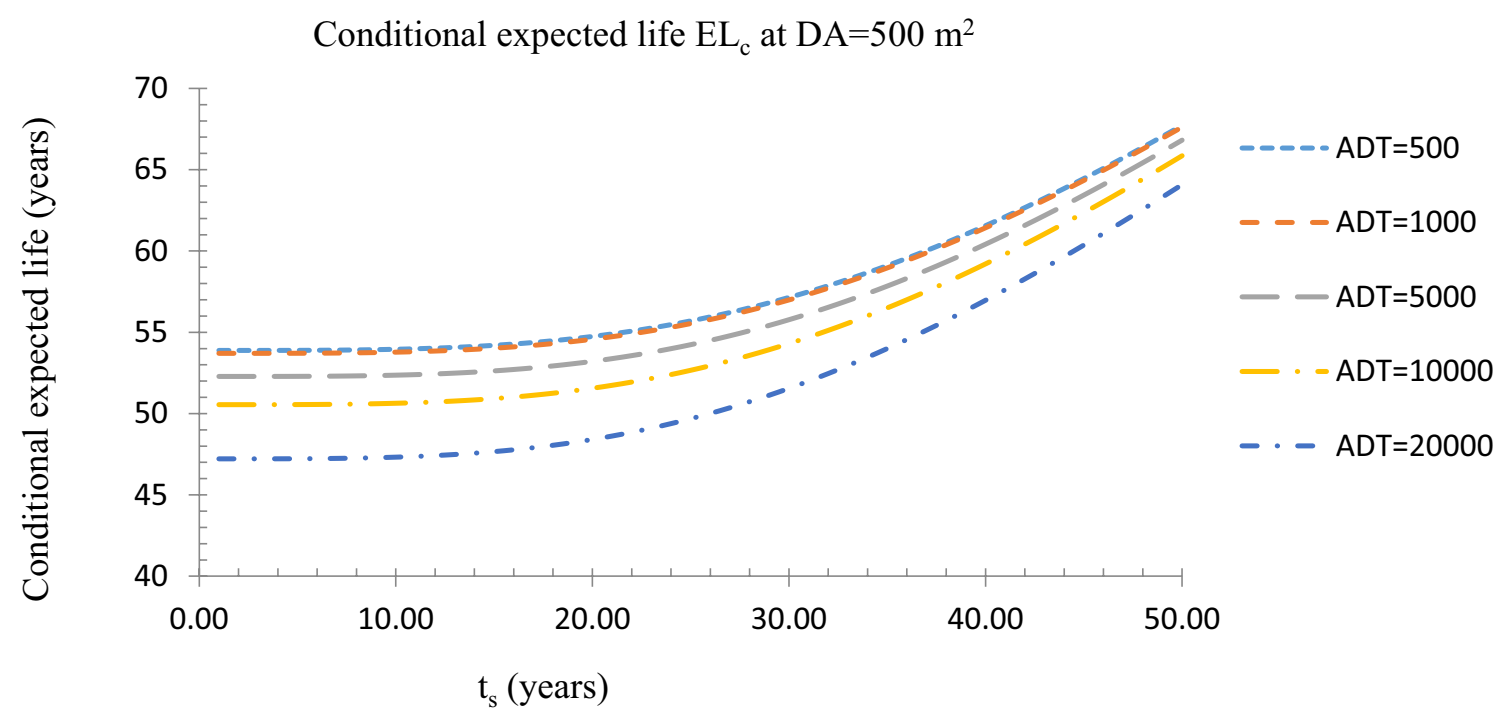

Fig. 8 Conditional expected life estimates of bridge decks with $\mathrm{DA}=500 \mathrm{~m}^{2}$ as a function of survived age

Conditional expected life $\mathrm{EL}_{\mathrm{c}}$ at $\mathrm{ADT}=5000$

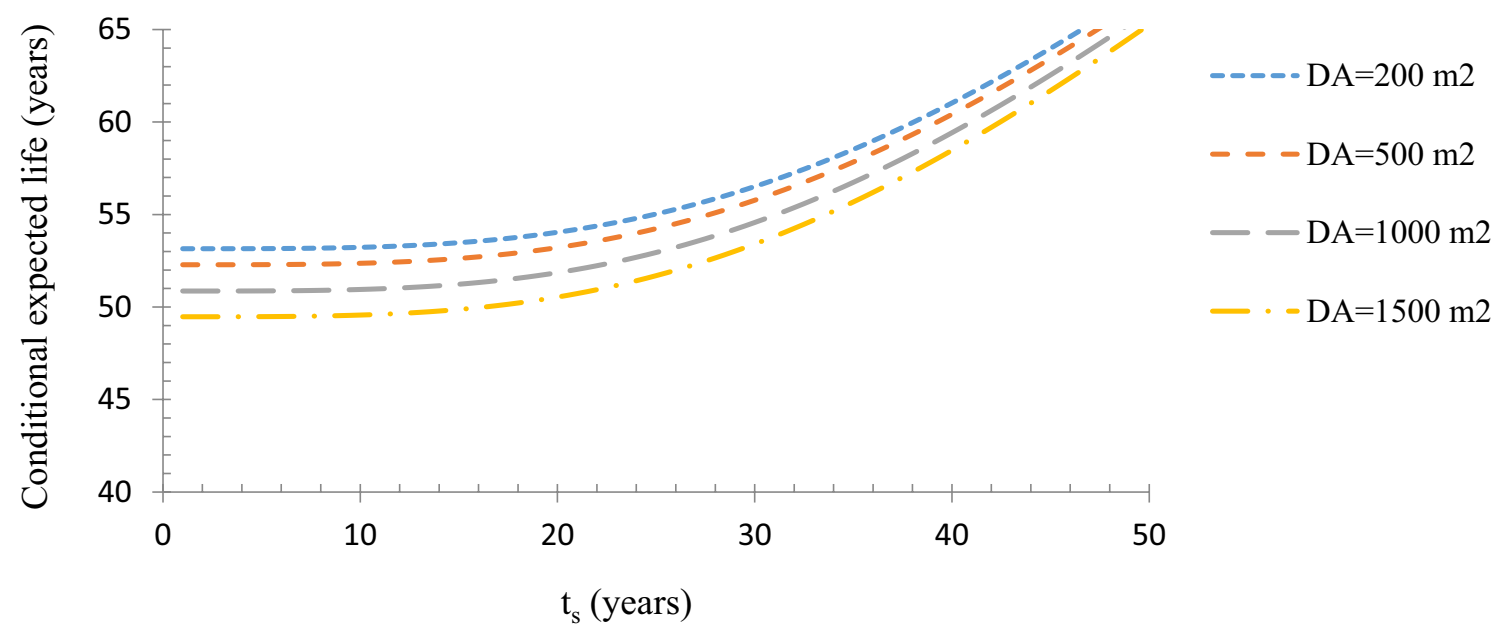

Fig. 9 Conditional expected life estimates of bridge decks with ADT $=5000$ as a function of survived age

ADT from 500 to 20,000 would reduce the expected life $\mathrm{EL}_{0}$ by roughly 6-7 years. On the other hand, changing the DA from 200 to $1500 \mathrm{~m}^{2}$ reduces $\mathrm{EL}_{0}$ by less than 2 years.

A detailed example illustrating the calculation processes for conditional survival and expected service life estimates is provided in Appendix.

\section{Summary and conclusions}

Probabilistic assessment of service life of bridge decks is an important consideration in support of effective long-term maintenance of bridges. In this study, conditional survival analysis techniques are applied to bridge decks to evaluate the end of service life using the NBI bridge records. A recorded NBI deck condition rating of five was considered the end of service life of bridge decks. The survival analysis procedures developed by Tabatabai et al. (2011) were extended to include conditional survival considerations. The covariates considered were the bridge age, ADT, and DA.

As bridge decks age without failure (reaching the end of service life), the survival probabilities change. The additional knowledge gained from the fact that a bridge deck has survived several years alters (increases) the original (bridge construction) probability of survival at subsequent years based on the conditional probability theory. The fact that 


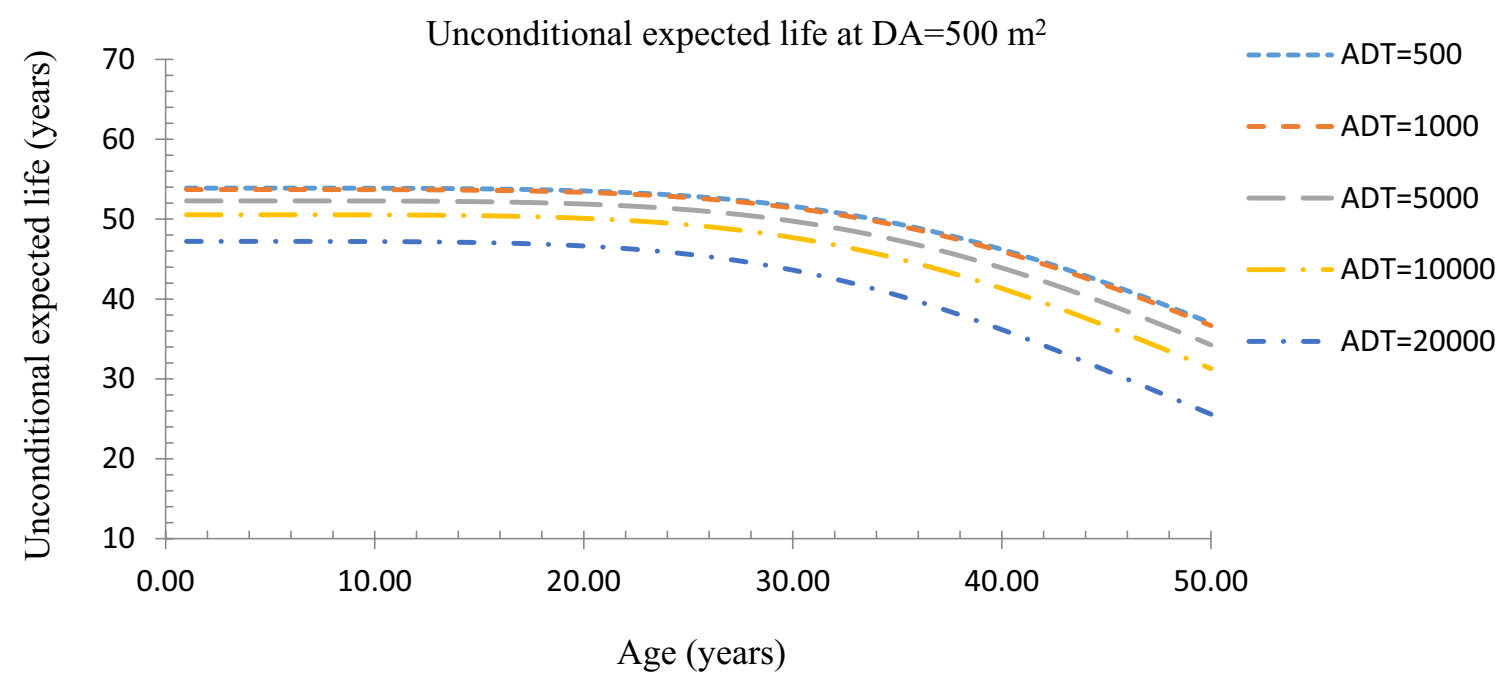

Fig. 10 Unconditional expected life estimates of bridge decks with $\mathrm{DA}=500 \mathrm{~m}^{2}$ as a function of age

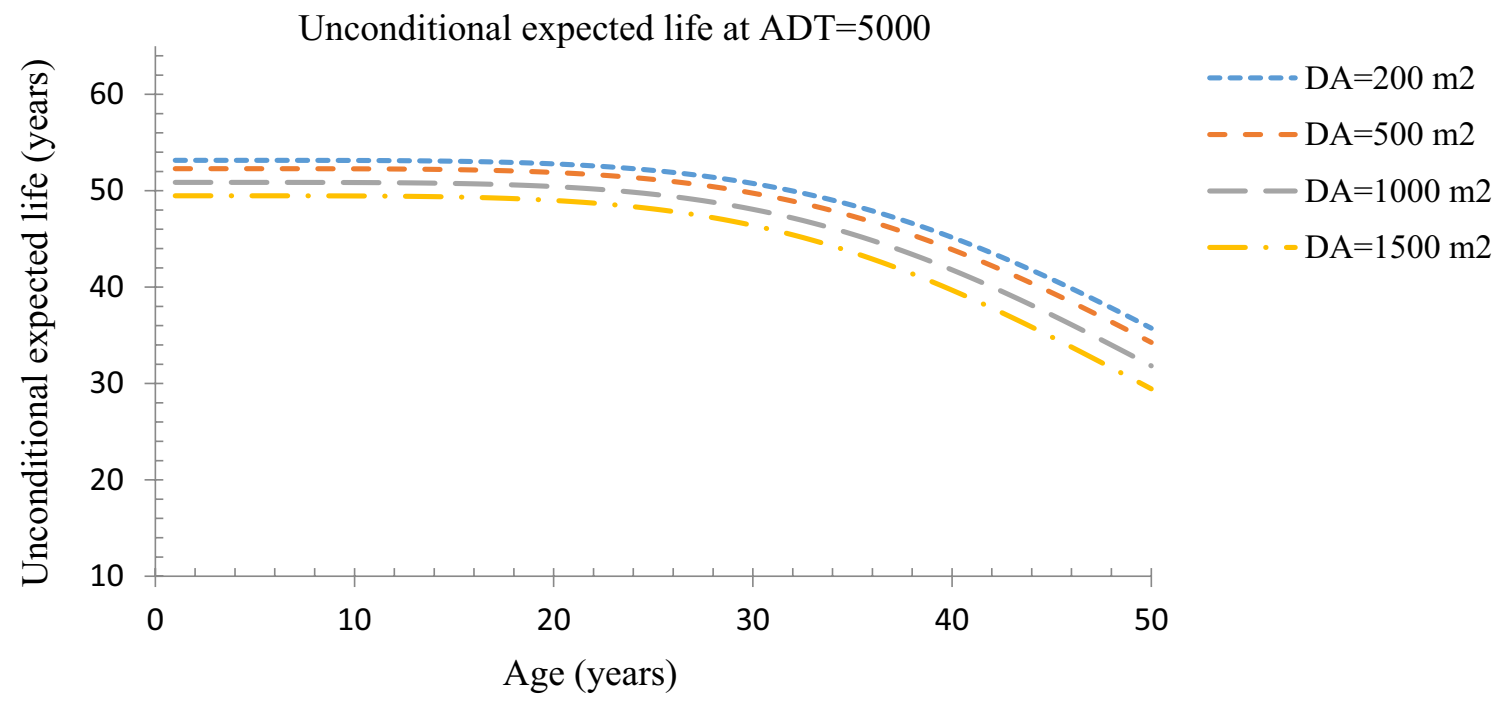

Fig. 11 Conditional expected life estimates of bridge decks with ADT $=5000$ as a function of age

Fig. 12 Representation of age when $\mathrm{EL}_{u}$ would begin rapid reduction

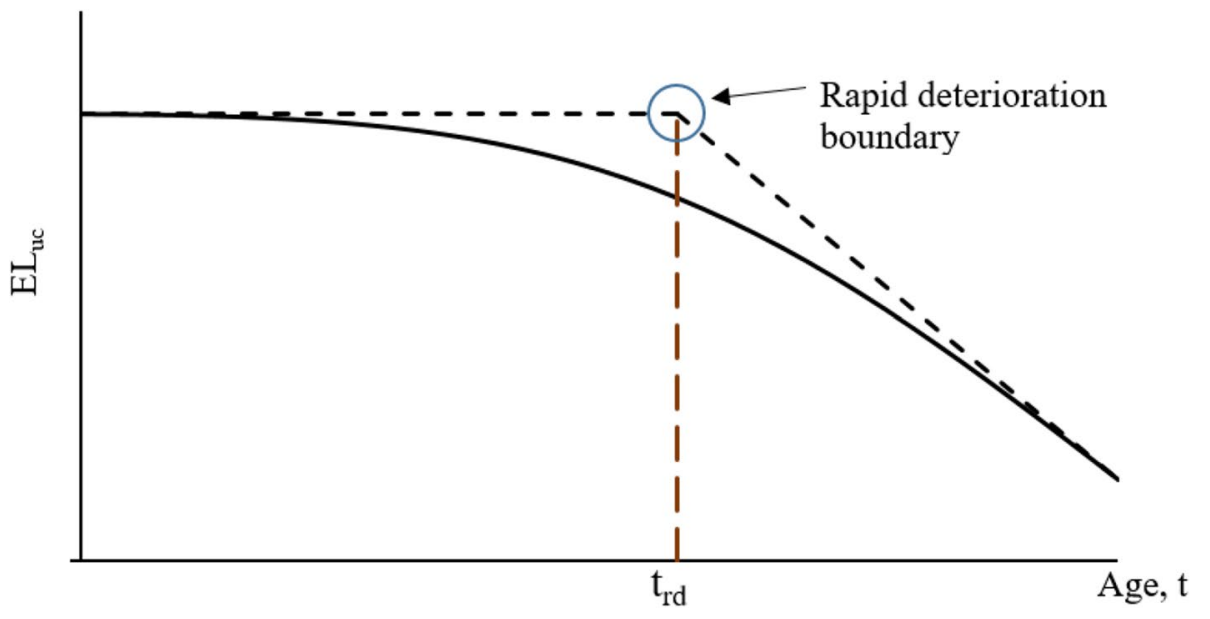


Table 4 Expected service life $\left(\mathrm{EL}_{0}\right)$ for various ADT and DA

\begin{tabular}{llllll}
\hline Expected service life (years) \\
\hline Deck area $\left(\mathrm{m}^{2}\right)$ & \multicolumn{5}{l}{ ADT (vehicles) } \\
\cline { 2 - 6 } & 500 & 1000 & 5000 & 10,000 & 20,000 \\
\hline 200 & 54.8 & 54.6 & 53.2 & 51.4 & 48.0 \\
500 & 53.9 & 53.7 & 52.3 & 50.5 & 47.2 \\
1000 & 52.4 & 52.3 & 50.9 & 49.2 & 45.9 \\
1500 & 51.0 & 50.8 & 49.5 & 47.8 & 44.6 \\
\hline
\end{tabular}

Table 5 Rapid deterioration age $\left(t_{r d}\right)$ for various $A D T$ and $D A$

\begin{tabular}{llllll}
\hline$t_{\text {rd }}$ (years) \\
\hline Deck area $\left(\mathrm{m}^{2}\right)$ & \multicolumn{5}{l}{ ADT (vehicles) } \\
\cline { 2 - 6 } & 500 & 1000 & 5000 & 10,000 & 20,000 \\
\hline 200 & 35.2 & 35.1 & 34.5 & 33.8 & 31.8 \\
500 & 34.8 & 34.8 & 34.2 & 33.3 & 31.2 \\
1000 & 33.6 & 33.5 & 32.7 & 31.7 & 29.0 \\
1500 & 34.2 & 34.2 & 33.5 & 32.5 & 30.2 \\
\hline
\end{tabular}

survival has been achieved at any given time $t_{\mathrm{s}}$ changes the probability of survival from $S\left(t_{\mathrm{s}}\right)$ to 1.0 . The probability of survival at subsequent times would also change by dividing the original survival function by $S\left(t_{\mathrm{s}}\right)$. A conditional survival function can thus be calculated for different $t$ and $t_{\mathrm{s}}$ values.

The expected service life of a bridge deck, without or with achieved survival years, can be estimated using the original and conditional survival functions, respectively. The area under the original survival function is equal to the expected life $\left(\mathrm{EL}_{0}\right)$ based on the state of knowledge at $t=0$. Relationships are provided to calculate the expected service life at various ages of the bridge deck. These estimates can be unconditional, based on knowledge at the time of construction of bridge deck, or conditional when $t_{\mathrm{s}}$ years of service have been achieved without reaching the end of service life.

The average daily traffic and deck surface area affect the survival probabilities and the expected life. As an example, changing ADT from 500 to 2000 would reduce the expected life (EL0) by 6-7 years based on Wisconsin data (when $\mathrm{DA}=500 \mathrm{~m}^{2}$ ). A parameter representing the age when the unconditional expected life begins to suffer rapid reduction $\left(t_{\mathrm{rd}}\right)$ has been defined and calculated for various ADT and DA values. This parameter can be another tool in planning of maintenance, repair, and replacement operations for bridge decks. In addition, an example is provided to illustrate calculations of overall survival, conditional survival, initial expected life, and conditional expected life.
It should be noted that although the procedures described in this paper apply to bridge decks in all geographic locations, the parameters $(\alpha, \beta, c$, and $d)$ that are used in the calculations are determined based on the 2016 Wisconsin NBI data. For all other states, these parameters have been determined by Tabatabai et al. (2015) and can be used in a similar fashion.

The information provided in this paper can be combined with cost information to determine the optimum maintenance interventions during the service life of bridge decks. Changes in the probability of survival during the life of a bridge deck should be considered to be a dynamic and changing value that must be assessed based on the conditional probability theory.

Open Access This article is distributed under the terms of the Creative Commons Attribution 4.0 International License (http://creativeco mmons.org/licenses/by/4.0/), which permits unrestricted use, distribution, and reproduction in any medium, provided you give appropriate credit to the original author(s) and the source, provide a link to the Creative Commons license, and indicate if changes were made.

\section{Appendix}

Example Consider a bridge deck in Wisconsin with a surface area of $1000 \mathrm{~m}^{2}$ and ADT of 5000 vehicles that was built 20 years ago. The bridge deck is performing well in service and has not reached the end of its service life (defined as deck condition rating of five). Using the NBI-based survival analysis, parameters described in this paper are determined:

1. Overall survival estimates at the ages of 20,40 , and 60 years [i.e., $S(20), S(40)$, and $S(60)$ ].

2. The expected life at the time of construction of the bridge deck.

3. The age corresponding to rapid deterioration $\left(t_{\mathrm{rd}}\right)$.

4. Considering that the bridge deck has already survived 20 years $\left(t_{\mathrm{s}}=20\right)$, what is the probability that it would survive another 20 years (i.e., reach the age of 40 ), or 40 years (i.e., reach the age of 60$)$ ?

5. The conditional expected life if the bridge deck had already survived 40 years $\left[\mathrm{EL}_{\mathrm{c}}(40)\right]$.

6. The unconditional expected life at 40 years $\left[\operatorname{EL}_{\mathrm{u}}(40)\right]$.

7. Estimate values of survival dividend $\left(\mathrm{SD}_{1}\right.$ and $\left.\mathrm{SD}_{2}\right)$ at the age of 40 years.

\section{Solution:}

1. According to Eqs. 6, 8, and 9 and using calculated parameters for Wisconsin bridges shown in Table 3: 


$$
\begin{aligned}
\alpha & =1.29 E-03 \\
\beta & =1.90 E+00 \\
c & =5.70 E-05 \\
d & =6.93 E-06 .
\end{aligned}
$$

At the age of 20 years:

$$
\begin{aligned}
t_{\mathrm{g}} & =(t) e^{[c(\mathrm{DA})+d(\mathrm{ADT})]} \\
& =(20) e^{[(5.70 E-05)(1000)+(6.93 E-06)(5000)]}=21.92
\end{aligned}
$$

$$
\begin{aligned}
W\left(t_{\mathrm{g}}\right) & =\alpha\left[1-t_{\mathrm{g}}^{\beta} \operatorname{coth}\left(t_{\mathrm{g}}^{\beta}\right)\right] / \beta \\
& =\frac{(1.29 \mathrm{E}-03)\left[1-21.92^{1.90} \operatorname{coth}\left(21.92^{1.90}\right)\right]}{1.9} \\
& =-0.239
\end{aligned}
$$

$S(20)=\operatorname{sech}\left\{W\left(t_{\mathrm{g}}\right)\right\}=\operatorname{sech}(-0.239)=0.972$.

Therefore, the probability of survival at the age of 20 is $97.2 \%$.

At the age of 40 years:

$$
\begin{aligned}
t_{\mathrm{g}} & =(t) e^{[c(\mathrm{DA})+d(\mathrm{ADT})]} \\
& =(40) e^{[(5.70 E-05)(1000)+(6.93 E-06)(5000)]}=43.83
\end{aligned}
$$

$$
\begin{aligned}
W\left(t_{\mathrm{g}}\right) & =\alpha\left[1-t_{\mathrm{g}}^{\beta} \operatorname{coth}\left(t_{\mathrm{g}}^{\beta}\right)\right] / \beta \\
& =\frac{(1.29 E-03)\left[1-43.83^{1.90} \operatorname{coth}\left(43.83^{1.90}\right)\right]}{1.9} \\
& =-0.893
\end{aligned}
$$

$S(40)=\operatorname{sech}\left\{W\left(t_{\mathrm{g}}\right)\right\}=\operatorname{sech}(-0.893)=0.701$

Therefore, the probability of survival at the age of 40 is $70.1 \%$.

At the age of 60 years:

$$
\begin{aligned}
& \begin{aligned}
t_{\mathrm{g}} & =(t) e^{[c(\mathrm{DA})+d(\mathrm{ADT})]} \\
& =(60) e^{[(5.70 E-05)(1000)+(6.93 E-06)(5000)]}=65.76 \\
W\left(t_{\mathrm{g}}\right) & =\alpha\left[1-t_{\mathrm{g}}^{\beta} \operatorname{coth}\left(t_{\mathrm{g}}^{\beta}\right)\right] / \beta \\
& =\frac{(1.29 \mathrm{E}-03)\left[1-65.76^{1.90} \operatorname{coth}\left(65.76^{1.90}\right)\right]}{1.9} \\
& =-1.931, \\
t_{\mathrm{g}} & =(t) e^{[c(\mathrm{DA})+d(\mathrm{ADT})]} \\
& =(60) e^{[(5.70 E-05)(1000)+(6.93 E-06)(5000)]}=65.76
\end{aligned}
\end{aligned}
$$

Therefore, the probability of survival at the age of 60 is $28.4 \%$.

2. According to Table 4, the expected life at the time of construction of the bridge deck is 50.9 years. This can also be determined by numerically integrating the entire survival function:

$\mathrm{EL}_{0}=\int_{0}^{\infty} S(t) \mathrm{d} t=50.9$ years.

3. According to Table $5, t_{\mathrm{rd}}$ is 33 years. This can also be determined by determining the two straight lines at the beginning and end zones of the $\mathrm{El}_{\mathrm{u}}$ curve, and finding the age associated with the intersection of those two lines.

4. According to Eq. 5, the conditional survival at the age of 40 considering survival at 20 years is

$\mathrm{CS}(t, s)=\frac{S(t)}{S(s)}$

$\mathrm{CS}(40,20)=\frac{S(40)}{S(20)}=\frac{0.701}{0.972}=0.721$.

The probability of reaching the age of 60 assuming that 20 years of survival has been achieved is

$\mathrm{CS}(60,20)=\frac{S(60)}{S(20)}=\frac{0.284}{0.972}=0.292$.

5. Conditional expected life when $t_{\mathrm{s}}=40$ years can be estimated using Eq. 10. The integration can be performed numerically (for example, using a spreadsheet):

$$
\begin{aligned}
\mathrm{EL}_{\mathrm{c}}(40) & =t_{\mathrm{s}}+\int_{t_{\mathrm{s}}}^{\infty} \frac{S(t)}{S\left(t_{\mathrm{s}}\right)} \mathrm{d} t=40+\frac{1}{S(40)} \int_{40}^{\infty} S(t) \mathrm{d} t \\
& =40+\frac{1}{0.701} 15.64=60.0 \text { years. }
\end{aligned}
$$

6. Unconditional expected life at 40 years can be estimated using Eqs. 11 and 12. The integration can be performed numerically:

$$
\begin{aligned}
\mathrm{EL}_{\mathrm{u}}(40) & =S(t) t+\int_{t}^{\infty} S(t) \mathrm{d} t=S(40) 40+\int_{40}^{\infty} S(t) \mathrm{d} t \\
& =(0.701) 40+14.0=42.0 \text { years. }
\end{aligned}
$$

7. Survival dividend $\left(\mathrm{SD}_{1}\right.$ and $\left.\mathrm{SD}_{2}\right)$ at age of 40 years are calculated by Eqs. 13 and 14 as

$\mathrm{SD}_{1}(40)=\mathrm{EL}_{\mathrm{c}}(40)-\mathrm{EL}_{0}=60.0-50.9=9.1$ years, 


$$
\begin{aligned}
\mathrm{SD}_{2}(40) & =\mathrm{EL}_{\mathrm{c}}(40)-\mathrm{EL}_{\mathrm{u}}(40) \\
& =60.0-42.0=18.0 \text { years. }
\end{aligned}
$$

\section{References}

Akgul F, Frangopol DM (2003) Rating and reliability of existing bridges in a network. J Bridge Eng 8(6):383-393

ASCE (2018). Infrastructure report card, american society of civil engineers. https://www.infrastructurereportcard.org/cat-item/bridges/. Accessed Dec 2018

Baade PD, Youlden DR, Chambers SK (2011) When do I know I am cured? Using conditional estimates to provide better information about cancer survival prospects. Med J Aust 194(2):73

Barone G, Frangopol DM (2014) Reliability, risk and lifetime distributions as performance indicators for life-cycle maintenance of deteriorating structures. Reliab Eng Syst Saf 123(2014):21-37

Beng SS, Matsumoto T (2012) Survival analysis on bridges for modeling bridge replacement and evaluating bridge performance. $\mathrm{J}$ Struct Infrastruct Eng 8(3):251-268

Brown MC, Gomez JP, Hammer ML, Hooks JM (2014) Long-term bridge performance high priority bridge performance issues (No. FHWA-HRT-14-052)

Bursac Z, Tabatabai M, Williams DK, Singh K (2008) A simulation study of performance of hypertabastic and hyperbolastic survival models in comparison with classic survival models. In: Proc. 2008 American statistical assoc. Biometrics section (CD-ROM), pp. $617-622$

Chang GJ, Hu CY, Eng C, Skibber JM, Rodriguez-Bigas MA (2009) Practical application of a calculator for conditional survival in colon cancer. J Clin Oncol 27(35):5938-5943

Fuller CD, Wang SJ, Thomas CR Jr, Hoffman HT, Weber RS, Rosenthal DI (2007) Conditional survival in head and neck squamous cell carcinoma: results from the SEER dataset 1973-1998. Cancer 109(7):1331-1343

Hieke S, Kleber M, König C, Engelhardt M, Schumacher M (2015) Conditional survival: a useful concept to provide information on how prognosis evolves over time. Clin Cancer Res 21(7):1530-1536

Janssen-Heijnen ML, Gondos A, Bray F, Hakulinen T, Brewster DH, Brenner H, Coebergh JWW (2010) Clinical relevance of conditional survival of cancer patients in Europe: age-specific analyses of 13 cancers. J Clin Oncol 28(15):2520-2528

Kato I, Severson RK, Schwartz AG (2001) Conditional median survival of patients with advanced carcinoma: surveillance, epidemiology, and end results data. Cancer 92(8):2211-2219

Kong JS, Frangopol DM (2003) Life-cycle reliability-based maintenance cost optimization of deteriorating structures with emphasis on bridges. J Struct Eng 129(6):818-828

Mauch M, Madanat S (2001) Semiparametric hazard rate models of reinforced concrete bridge deck deterioration. J Bridge Eng ASCE $7(2): 49-57$

Merrill RM, Hunter BD (2010) Conditional survival among cancer patients in the United States. Oncologist 15(8):873-882

Merrill RM, Henson DE, Barnes M (1999) Conditional survival among patients with carcinoma of the lung. Chest 116(3):697-703

Nabizadeh A. (2015). Reliability of bridge superstructures in wisconsin. Master's Thesis. Department of Civil and Environmental Engineering, University of Wisconsin-Milwaukee, Milwaukee, Wisconsin, United States
Nabizadeh A, Tabatabai H, Tabatabai M (2018) Survival analysis of bridge Superstructures in Wisconsin. Appl Sci 8(11):2079

Nikulin M, Wu H-DI (2016) The cox model and its application. Springer, Berlin. https://doi.org/10.1007/978-3-662-49332-8

Parsons HM, Habermann EB, Tuttle TM, Al-Refaie WB (2011) Conditional survival of extremity soft-tissue sarcoma: results beyond the staging system. Cancer 117(5):1055-1060

Sun J, Hong HP (2001) Effect of reinforcement corrosion on reliability of bridge girders. Civ Eng Environ Syst 19(1):67-85

Tabatabai MA, Bursac Z, Williams DK, Singh KP (2007) Hypertabastic survival model. Theor Biol Model. https://doi. org/10.1186/1742-4682-4-40

Tabatabai H, Tabatabai M, Lee CW (2011) Reliability of bridge decks in Wisconsin. J Bridge Eng ASCE 2011(16):53-62

Tabatabai H, Lee CW, Tabatabai M (2015) Reliability of bridge decks in the United States. Bridge Struct J IOS Press 11(2015):75-85

Tabatabai H., Lee C.-W., Tabatabai M. A. (2016). Survival analyses for bridge decks in Northern United States. Civil and Environmental Engineering Faculty Article, Paper 7, University of WisconsinMilwaukee, http://dc.uwm.edu/cee_faeart/7

Tabatabai H, Nabizadeh A, Tabatabai M (2018) Overview of survival analysis techniques for probabilistic assessment of bridge service life. In: 17th International conference and exhibition, May 15-17, 2018, Edinburgh, UK

Tahir MR, Tran QX, Nikulin MS (2017) Comparison of hypertabastic survival model with other unimodal hazard rate functions using a goodness-of-fit test. Stat Med 36(12):1936-1945

Tran XQ (2014) Dynamics regression models and their application in survival and reliability analysis. Ph.D. Dissertation, Universite de Bordeux, France, https://tel.archives-overtes.fr/tel-01201910

Wang SJ, Emery R, Fuller CD, Kim JS, Sittig DF, Thomas CR (2007) Conditional survival in gastric cancer: a SEER database analysis. Gastric Cancer 10(3):153-158

Xing Y, Chang GJ, Hu CY, Askew RL, Ross MI, Gershenwald JE, Lee JE, Mansfield PF, Lucci A, Cormier JN (2010) Conditional survival estimates improve over time for patients with advanced melanoma: results from a population-based analysis. Cancer 116(9):2234-2241

Yang YN, Kumaraswamy MM, Pam HJ, Xie HM (2013) Integrating semiparametric and parametric models in survival analysis of bridge element deterioration. J Infrastruct Syst 19:176-185

Yu XQ, Baade PD, O'Connell DL (2012) Conditional survival of cancer patients: an Australian perspective. BMC Cancer 12(1):460

Zabor EC, Gonen M, Chapman PB, Panageas KS (2013) Dynamic prognostication using conditional survival estimates. Cancer 119(20):3589-3592

Zamboni BA, Yothers G, Choi M, Fuller CD, Dignam JJ, Raich PC, Thomas CR Jr, O'Connell MJ, Wolmark N, Wang SJ (2010) Conditional survival and the choice of conditioning set for patients with colon cancer: an analysis of NSABP trials C-03 through C-07. J Clin Oncol 28(15):2544

Zhu W, Setunge S, Gamage N, Gravina R, Venkatesan S (2017) Evaluating Time-dependent reliability and probability of failure of reinforced-concrete bridge components and predicting residual capacity after subsequent rehabilitation. J Perform Constr Facilit 31(3):04017005

Publisher's Note Springer Nature remains neutral with regard to jurisdictional claims in published maps and institutional affiliations. 